\title{
Oversampling of sedimentary series collected by giant piston corer: Evidence and corrections based on $3.5-\mathrm{kHz}$ chirp profiles
}

\author{
Nadia Széréméta, ${ }^{1,2}$ Franck Bassinot, ${ }^{3,4}$ Yvon Balut, ${ }^{5}$ Laurent Labeyrie,, 2 \\ and Maurice Pagel ${ }^{1}$ \\ Received 5 April 2002; revised 24 February 2003; accepted 23 September 2003; published 29 January 2004.
}

[1] The depth-scale accuracy of marine sedimentary series collected by coring is of key importance for the precise calculation of sedimentation rates and fluxes. For three giant piston cores collected during the InterPole MD99-114/International Marine Past Global Changes Study (IMAGES) V cruise (MD99-2227, MD99-2246, and MD99-2251), the $3.5-\mathrm{kHz}$ chirp profiles recorded on board are compared to synthetic seismograms computed from physical property logs measured on cores. In each case, the perfect match of main deep reflectors requires a significant upward shift of the water-sediment $(\mathrm{W} / \mathrm{S})$ interface in the synthetic seismograms with respect to the $3.5-\mathrm{kHz}$ profiles. Since no drastic perturbation of the physical property logs is observed, this upward shift is interpreted as resulting from a significant sediment oversampling in the upper part of the cores. The affected depth intervals are consistent with the thickness of the perturbed zones observed in penetrometry and anisotropy of magnetic susceptibility records $(\sim 10-15 \mathrm{~m})$. To retrieve the true in situ sediment thickness, a linear depth correction is applied between consecutive acoustic reflectors to achieve a perfect match between the synthetic seismogram and the corresponding 3.5-kHz profiles. Depth correction laws (amount of material excess as a function of initial depth) are deduced from this resynchronization procedure. First estimations of upper core oversampling rates range from 30\% (core MD99-2227) to 37\% (core MD99-2246). Moreover, we observe that some undersampling may also exist in the lower part of the sediment cores. INDEX TERMS: 1635 Global Change: Oceans (4203); 4259 Oceanography: General: Ocean acoustics; 4294 Oceanography: General: Instruments and techniques; KEYWORDS: correction of coring-induced sediment oversampling, giant piston coring, IMAGES cores, North Atlantic

Citation: Széréméta, N., F. Bassinot, Y. Balut, L. Labeyrie, and M. Pagel (2004), Oversampling of sedimentary series collected by giant piston corer: Evidence and corrections based on 3.5-kHz chirp profiles, Paleoceanography, 19, PA1005, doi:10.1029/ 2002PA000795.

\section{Introduction}

[2] The thickness of marine sedimentary series is an essential parameter in the calculation of sedimentation rates and fluxes. However, investigations to check the accuracy of depth scale in marine cores retrieved by coring and/or drilling devices are still too rarely performed.

[3] Within the International Marine Past Global Changes Study (IMAGES) a debate has been initiated about possible "oversampling" and/or "stretching" of sedimentary series collected by giant piston corers [Labeyrie et al., 2003; Skinner and McCave, 2001]. This discussion was mostly based on the comparison of

\footnotetext{
${ }^{1}$ Département des Sciences de la Terre, Université Paris-Sud, Orsay, France.

${ }^{2}$ Also at Laboratoire des Sciences du Climat et l'Environnement, CEACNRS, Gif-sur-Yvette, France.

${ }^{3}$ Laboratoire des Sciences du Climat et l'Environnement, CEA-CNRS, Gif-sur-Yvette, France.

${ }^{4}$ Also at Department of Earth Sciences, University of Cambridge, Cambridge, UK.

${ }^{5}$ Institut Polaire Français Paul Emile Victor, Plouzané, France.

Copyright 2004 by the American Geophysical Union. 0883-8305/04/2002PA000795
}

sedimentary records retrieved with the Calypso corer, which equips the $\mathrm{R} / \mathrm{V}$ Marion Dufresne with some "reference" records obtained at the same sites with other coring or drilling devices (i.e., short Kullenberg cores and Ocean Drilling Program (ODP) hydraulic piston cores). In many cases, the upper part of the Calypso records appears to be expanded compared to the other records (see examples given by Labeyrie et al. [2003]). However, this relative expansion is not always observed. When layering is preserved, there is usually no evidence of systematic, strong deformation of Calypso records (such as flow-in structures) in the upper part of the cored series. Furthermore, good quality, well-dated stable isotopic records have been obtained on numerous Marion Dufresne giant cores, attesting that material retrieved does not present obvious stratigraphic disturbance related to coring [i.e., Bassinot et al., 1994; Shackleton et al., 2000; Visser et al., 2003].

[4] During the InterPole MD99-114/IMAGES V cruise, several penetrometry tests and anisotropy of magnetic susceptibility (AMS) measurements were performed on board. The low sediment cohesion and anomalous (vertical) magnetic fabric clearly indicate that sediments experienced significant perturbations in the upper part of most of the cores studied. The thicknesses of the upper perturbed zones vary from 10 to $15 \mathrm{~m}$ depth [Labeyrie et al., 2003] 


\section{a}

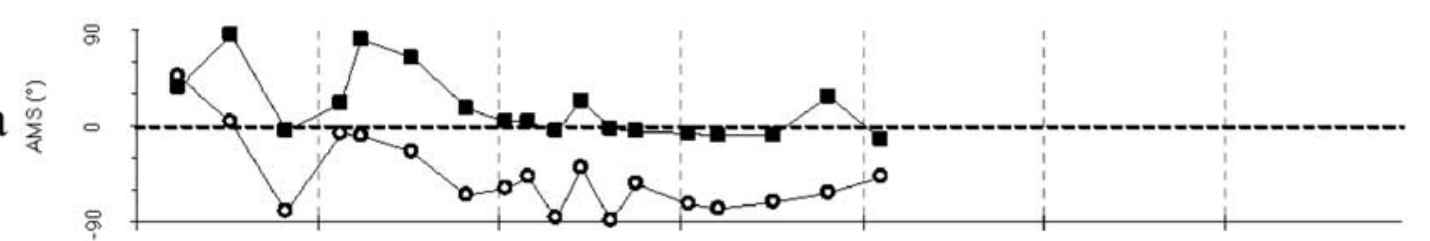

$\mathrm{b}$

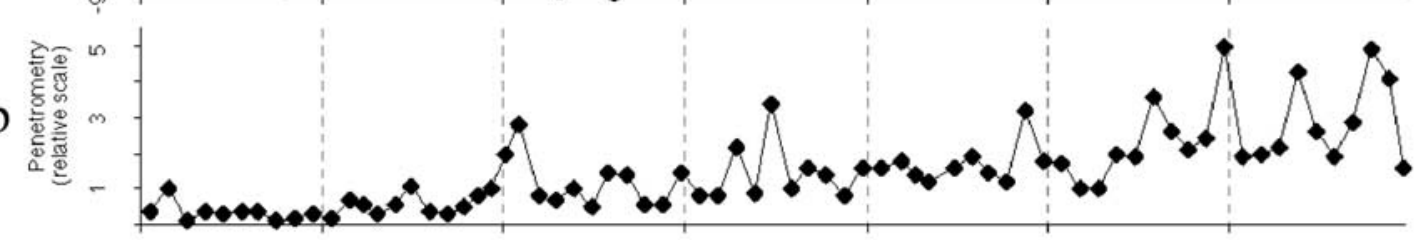

c

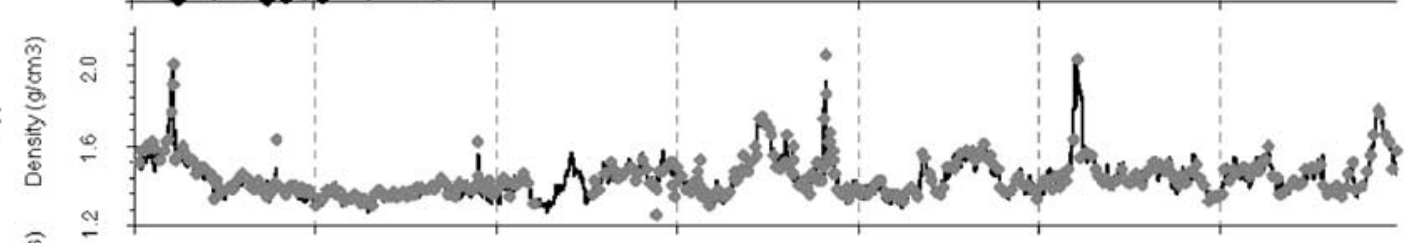

d
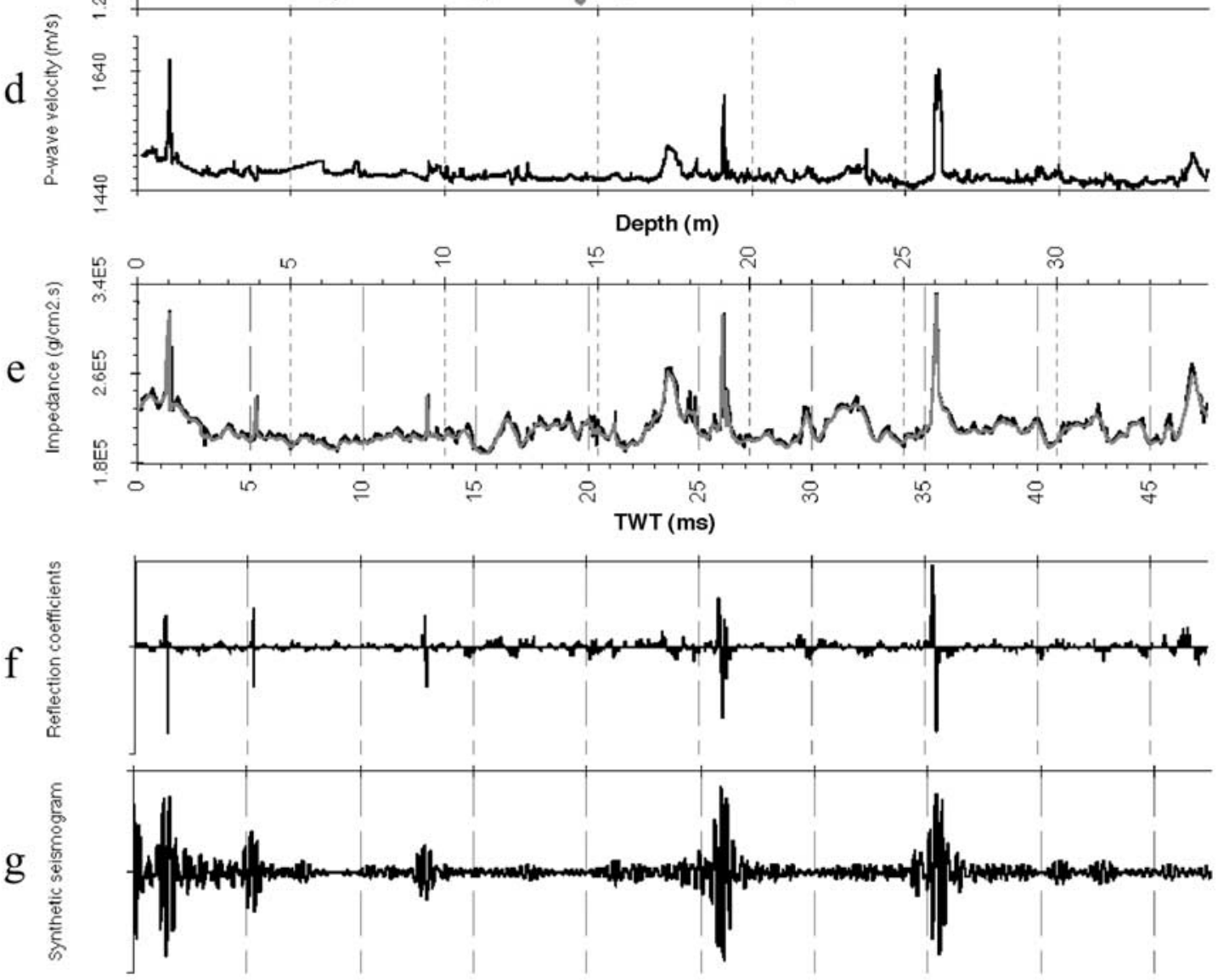

Figure 1. For core MD99-2246: Comparison of physical property logs (Figures 1c, 1d, and 1e) with AMS (Figure 1a) and penetrometry (Figure 1b) data, reflection coefficients (Figure 1f), and synthetic seismograms (Figure 1g). (a) AMS versus depth: black squares, inclination of maximum grain axis; open circles, inclination of minimum grain axis. (b) Penetrometry versus depth: cohesion coefficients ranging from 0 to 5. (c) Density $\left(\mathrm{g} \mathrm{cm}^{-3}\right)$ versus depth: black line, gamma-densimetry; gray diamonds, helium pycnometry. (d) Velocity $\left(\mathrm{m} \mathrm{s}^{-1}\right)$ versus depth. (e) Impedance $\left(\mathrm{g} \mathrm{cm}^{-2} \mathrm{~s}^{-1}\right)$ versus both depth and twoway travel time (TWT): black line, raw data; gray line, filtered data. (f) Reflection coefficients (dimensionless) versus TWT. (g) Synthetic seismogram versus TWT. Anomalous vertical reorientation of the magnetic fabric $\left(K_{\max }\right.$ inc. $\sim 90^{\circ}$ and $K_{\min }$ inc. $\left.\sim 0\right)$ and low cohesion (coefficient $\left.\leq 1\right)$ are observed in the upper $9 \mathrm{~m}$, an interval in which density and velocity logs do not show anomalous values. 
Table 1. Metadata and Summary of Sedimentological and Physical Property Data for Cores MD99-2227, MD99-2246, and MD99-2251

\begin{tabular}{|c|c|c|c|}
\hline & \multicolumn{3}{|c|}{ Core Name } \\
\hline & MD99-2227 & MD99-2246 & MD99-2251 \\
\hline Longitude & $48^{\circ} 22.32^{\prime} \mathrm{W}$ & $36^{\circ} 21.5^{\prime} \mathrm{W}$ & $27^{\circ} 54.47^{\prime} \mathrm{W}$ \\
\hline Latitude & $58^{\circ} 12.64^{\prime} \mathrm{N}$ & $61^{\circ} 54.7^{\prime} \mathrm{N}$ & $57^{\circ} 26.87^{\prime} \mathrm{N}$ \\
\hline Water depth & $3460 \mathrm{~m}$ & $2750 \mathrm{~m}$ & $2620 \mathrm{~m}$ \\
\hline In situ temperature & $2.6^{\circ} \mathrm{C}$ & $3.03^{\circ} \mathrm{C}$ & $3.16^{\circ} \mathrm{C}$ \\
\hline Core length & $42.16 \mathrm{~m}$ & $34.85 \mathrm{~m}$ & $36.41 \mathrm{~m}$ \\
\hline Sediment description & $\begin{array}{l}\text { dark grey, silty clay with biogenic silica; } \\
\text { shows several centimeter-scale } \\
\text { sandy mud beds rich in detrital } \\
\text { carbonate or thinly laminated beds } \\
\text { of quartzitic sand and silt }\end{array}$ & $\begin{array}{l}\text { siliciclastic sediment } \\
\text { with only minor biogenic material; } \\
\text { occurrences of sharp-based, laminated, } \\
\text { graded sand and silt beds, } \\
\text { and upward coarsening sandy beds }\end{array}$ & $\begin{array}{l}\text { silty clay; appears rather } \\
\text { uniform in grain size; } \\
\text { color changes from olive } \\
\text { grey on top, } \\
\text { to brown at the base, } \\
\text { gradually lightening downward }\end{array}$ \\
\hline \multicolumn{4}{|l|}{ Physical properties } \\
\hline $\begin{array}{l}\text { AMS } \\
\text { Penetrometry }\end{array}$ & $\begin{array}{l}\rho_{\mathrm{m}}=1.476 \mathrm{~g} \mathrm{~cm}^{-3} \\
V_{p \mathrm{~m}}(\mathrm{amb})=1467 \mathrm{~m} \mathrm{~s}^{-1} \\
V_{p \mathrm{~m}}(\text { in situ })=1471 \mathrm{~m} \mathrm{~s}^{-1} \\
\text { perturbed down to } \sim 15 \mathrm{~m}\end{array}$ & $\begin{array}{l}\rho_{\mathrm{m}}=1.451 \mathrm{~g} \mathrm{~cm}^{-3} \\
V_{p \mathrm{~m}}(\mathrm{amb})=1473 \mathrm{~m} \mathrm{~s}^{-1} \\
V_{p \mathrm{~m}}(\text { in situ })=1468 \mathrm{~m} \mathrm{~s}^{-1} \\
\text { perturbed down to } \sim 10 \mathrm{~m} \\
\text { low values down to } \sim 10 \mathrm{~m}\end{array}$ & $\begin{array}{l}\rho_{\mathrm{m}}=1.345 \mathrm{~g} \mathrm{~cm}^{-3} \\
V_{p \mathrm{~m}}(\mathrm{amb})=1474 \mathrm{~m} \mathrm{~s}^{-1} \\
V_{p \mathrm{~m}}(\text { in situ })=1466 \mathrm{~m} \mathrm{~s}^{-1} \\
\text { perturbed down to } \sim 10-12.5 \mathrm{~m}\end{array}$ \\
\hline
\end{tabular}

(Figures 1a and 1b). However, penetrometry and AMS profiles poorly inform us about origins and consequences of such disturbances. Indeed, for these perturbed cores, density/porosity/velocity values do not appear to be affected: Values obtained over these upper intervals are consistent with those observed in the lower part of the cores (example for core MD99-2246: Figures 1c and 1d).

[5] Because the depth scale is of key importance for sedimentation rate and flux estimations, serious investigations should be performed to test its accuracy. To establish whether there is a substantial depth disturbance in some marine cores, one must refer to a true in situ layer thickness of the sedimentary series. The comparison with other, non-Calypso records is not fully satisfactory since one does not know a priori that the "reference" records are not disturbed themselves (oversampled, undersampled, or compacted, for example). There is, indeed, some evidence that coring distortions could also significantly affect sedimentary series retrieved with other coring devices [Buvkley et al., 1994; Parker and Sills, 1990]. Thus, in this study, we propose to use as our references the on-site $3.5-\mathrm{kHz}$ profiles obtained from the R/V Marion Dufresne chirp profiler system during the coring operation. At each site, synchronization of the $3.5-\mathrm{kHz}$ profile with the synthetic seismogram computed from physical property logs obtained on the core (corrected to in situ pressure and temperature, $P-T$, conditions) will allow us to check for the proper recovery of the stratigraphic sequence. If discrepancies are observed, we propose to correct the depth scale in the cores by matching the main reflectors in the synthetic seismograms to their counterparts in the corresponding $3.5-\mathrm{kHz}$ profiles. This approach, which we propose to call "resynchronization," will be shown in detail in this paper for three cores collected in the North Atlantic during leg 2 of the InterPole MD99-114/ IMAGES V cruise in 1999: cores MD99-2227, MD992246, and MD992251 (Table 1). Complete onboard data sets are available from the cruise report [Labeyrie et al., 2003].

\section{Methods}

[6] Synthetic seismogram computation simulates the acoustic response of a sediment column characterized by its impedance profile $\rho V_{p}$, where $\rho$ is the wet bulk density and $V_{p}$ is the $P$ wave velocity. Impedance is mostly driven by density changes, and thus the accuracy of the density profile is of key importance to confidently compute the acoustic reflectors. Good $V_{p} \log$ accuracy is necessary to achieve a correct depth to travel time conversion for the precise comparison of the cored sediment series to the corresponding $3.5-\mathrm{kHz}$ profiles.

[7] First estimations of $\rho$ and $V_{p}$ logs were obtained as a function of depth on whole core sections with a Geotek Multi Sensor Track (MST) logger. For cores MD99-2246 and MD99-2251 these data sets were improved by discrete analyses performed directly on sedimentary material. High and rapid peak fluctuations were specially checked. We used a helium pycnometer and an electronic balance (for precise calculation of bulk densities), as well as a digital sound velocimeter (IKB Technologies Limited, Bedford, Canada, http://www.seistec.com/index.html), which precisely determines $P$ wave velocity from the insertion of piezoelectric transducers within the sediments. $V_{p}$ logs were corrected for in situ temperature and hydrostatic pressure conditions (Table 1) using the ratio method [Hamilton, 1971]. Corrections are insignificant for density profiles [Hamilton, 1971; Siedler and Peters, 1986; Breitzke, 2000]. Figures 1c and 1d show, as an example, the $\rho$ and $V_{p}$ (in situ) logs obtained for core MD99-2246. Mean density and $P$ wave velocity values (for ambient and in situ conditions) are reported in Table 1 for each core. These values are consistent with those generally observed in fine-grained, detrital environments, i.e., very low $P$ wave velocities for densities around $1.35-1.47 \mathrm{~g} \mathrm{~cm}^{-3}$ [Weber, 1998; Weber et al., 1997]. Moreover, one can note that the 


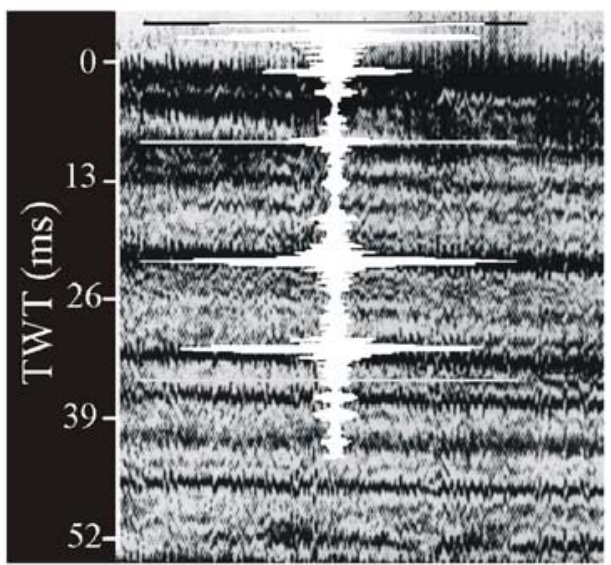

Figure 2. Comparison of the synthetic seismogram of core MD99-2246 with the corresponding 3.5-kHz profile. The synchronization between the deepest reflectors requires a significant upward shift of the water-sediment (W/S) interface in the synthetic seismogram with respect to its counterpart in the $3.5-\mathrm{kHz}$ profile. Cores MD99-2227 and 51 show the same features [Bassinot et al., 2001; Széréméta et al., 2000].

temperature effect (dominant for cores MD99-2246 and MD99-2251) tends to reduce $V_{p \text { (in situ) }}$ values while it is compensated for by the pressure effect on velocities of the deeper core MD99-2227.

[8] The algorithm developed to compute synthetic seismograms is based on a simple model of plane wave propagation in normal incidence, reflecting on infinite horizontal plane interfaces with no attenuation and no multiple. Thus the reflection coefficients can be strictly expressed in terms of impedance contrasts (first derivative of the $\rho V_{p} \log$ ) [Mayer, 1980; Mayer et al., 1985]. The depth scales are converted into two-way travel time scales (TWT) using the in situ corrected $V_{p}$ profiles. Synthetic seismograms are obtained by the convolution of the TWT reflection coefficient profiles with the acoustic source [Breitzke, 2000; Mayer, 1980; Mayer et al., 1985]. As the source, we use in this study a numerical chirp function similar to the excitation source of the $3.5-\mathrm{kHz}$ profiler that equips the R/V Marion Dufresne (sine function with frequencies varying linearly between $f_{\min }=$ $2.95 \mathrm{kHz}$ and $f_{\max }=4.55 \mathrm{kHz}$ and with a pulse duration $T=50 \mathrm{~ms}$ ). Finally, a cross-correlation with the source function is applied on synthetic seismograms to be consistent with the numerical processing of the $3.5-\mathrm{kHz}$ profiles. Both reflection coefficient and synthetic seismogram profiles versus two-way travel time are presented in Figures $1 \mathrm{f}$ and $1 \mathrm{~g}$ as an example for core MD99-2246.

[9] The raw MST density and velocity logs were sampled at $2-\mathrm{cm}$ intervals. Thus impedance logs show very high frequency (but low-amplitude) variability between major peaks related to main sedimentary changes. Part of this variability is attributed to analytical noise. Smoothing this variability by applying a moving average window proved to strengthen the main reflectors by improv- ing the signal/noise ratio and enhancing, therefore, the physical property changes related to true lithological changes. Raw and smoothed impedance logs obtained for core MD99-2246 are plotted in Figure 1e as a function of both depth and TWT scales. Figure 1 shows that major reflectors are related to sharp peaks in the impedance profile that are due to density fluctuations. Unpublished grain size results show that these sharp peaks could be associated with coarser sandy layers. Additional data are needed to draw conclusions as to the relationship between sedimentology and physical properties.

\section{Results}

[10] The synthetic seismogram obtained for core MD992246 is presented in Figure 2 superimposed on the corresponding $3.5-\mathrm{kHz}$ profile (as a function of TWT scale).

[11] We can obtain a good match between the deepest synthetic reflectors and their $3.5-\mathrm{kHz}$ counterparts. However, this deep "synchonization" results in the significant upward shift of the water-sediment (W/S) interface reflector in the synthetic seismograms with respect to its counterpart in the $3.5-\mathrm{kHz}$ profiles. This indicates that the TWT between the W/S interface and the first synchronized deep reflector in the synthetic seismograms is significantly longer than its counterpart in the corresponding $3.5-\mathrm{kHz}$ profile.

[12] This TWT expansion could result either from an abnormal increase of the upper sediment thickness (erroneous depth scale) or from anomalous low velocities in the upper part of the series (erroneous velocity law). No significant change is observed between mean velocity values calculated from the top and bottom parts of each core (example for core MD99-2246, Figure 1), and $V_{p}$ values are consistent with those generally obtained in water-saturated, fine-grained, siliciclastic sediments [Weber, 1998]. Moreover, we estimated that mean velocity should be increased by about $700 \mathrm{~m} \mathrm{~s}^{-1}$ in order to properly match the upper part of the synthetic seismogram (down to the first synchronized deep reflector) to the $3.5-\mathrm{kHz}$ record. Such a velocity correction would lead to unrealistic absolute $P$ wave velocity values for this type of sediment. So we interpret this TWT "expansion" as indicative of an oversampling of the upper part of the collected cores.

[13] By "oversampling," one should not understand "stretching" because that would be associated with anomalously high porosities (low densities), which are not observed in the upper part of physical property logs. We rather mean an anomalous thickening of the upper sediment layers resulting from an excess of sedimentary material being incorporated into the corer during the coring procedure.

\section{Discussion}

\subsection{Stacking Procedure}

[14] In order to obtain quantitative estimates for oversampling rates and to develop a correction procedure to calculate true sediment thickness, it appears necessary to 

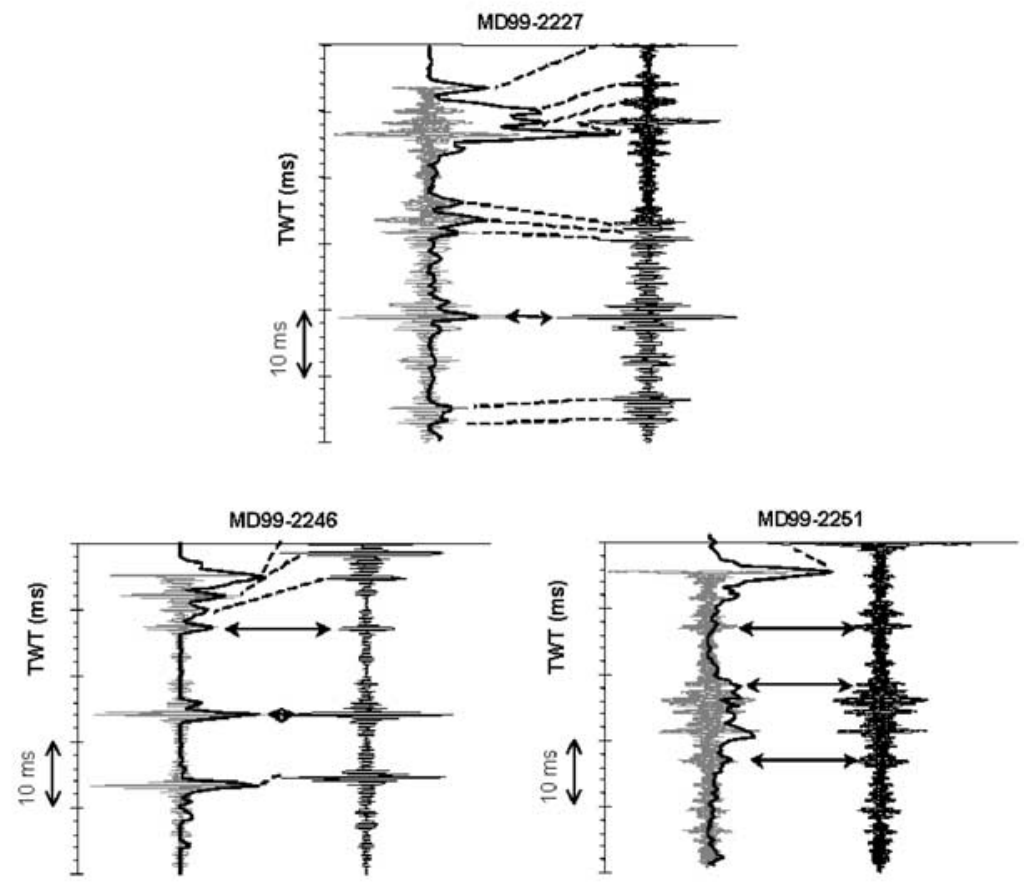

Figure 3. For the three cores, the figures show the following: on the right side, the raw synthetic profile; on the left side, the $3.5-\mathrm{kHz}$ reference data (envelope of the stacked traces, black bold line) overlaid with the resynchronized profile (fine gray line). Relative TWT is reported as vertical axis (10 ms between major tick marks, 2 ms between minor). Synchronized deep reflectors are linked with a black double arrow. Dashed lines highlight the lower reflectors used for the resynchronization procedure.

improve the quality of our "in situ references." To that aim, we computed coherent stacks of individual $3.5-\mathrm{kHz}$ traces recorded while the ship was holding the same geographical position, preparing for the coring operation. For cores MD99-2227, MD99-2246, and MD99-2251, 49, 38, and 79 individual traces were stacked, respectively. A threshold filter is then applied to minimize the noise and strengthen the main reflectors. Finally, a Hilbert transform provides the stack envelope, which will be used as our "in situ reference."

\subsection{Estimation of Oversampling Rates}

[15] For each site, Figure 3 shows, on the right side, the raw synthetic seismogram and, on the left side, the corresponding $3.5-\mathrm{kHz}$ stack envelope (black bold lines) overlaid with the resynchronized synthetic profile (fine gray lines). Relative TWT is used as the vertical axis (in milliseconds). The synchronization of the deep reflectors (indicated with black double arrows) implies a TWT shift of the W/S interfaces, which ranges between $6.6 \mathrm{~ms}$ for core MD99-2227, $5 \mathrm{~ms}$ for core MD99246, and $4.3 \mathrm{~ms}$ for core MD99-2251. On the basis of mean in situ $P$ wave velocities (Table 1) the TWT shifts translate into an excess material thickness of about $4.9 \mathrm{~m}$ for core MD99-2227, $3.7 \mathrm{~m}$ for core MD99-2246, and 3.1 m for core MD99-2251.

[16] These first estimates were used as starting points for a more accurate depth-scale correction procedure that is based on the "resynchronization" of the main intermediate reflectors (indicated with dashed lines in Figure 3). Between each of the consecutive impedance peaks we applied a simple linear depth correction, assuming therefore a simplistic perturbation model in which expansion during coring is evenly distributed along intervals with homogeneous physical properties. Synthetic seismograms were then recomputed and compared with the $3.5-\mathrm{kHz}$ stacks. After a few iterative depth-scale corrections, a satisfactory adjustment of the synthetic seismograms and the $3.5-\mathrm{kHz}$ stacks is obtained (fine gray line wiggle trace in Figure 3).

[17] Figure 4 presents the final depth correction laws obtained for the three cores. The cumulative excess of material thickness (in meters) is reported as a function of initial (uncorrected) depth (symbols indicate the initial positions of the tuned reflectors used for resynchronization). Line slopes between two tuned points give an estimation of the partial oversampling rate in the corresponding (uncorrected) depth interval.

[18] For the three series, the overall global oversampling tendency (positive slope) is largely dominant in the upper $20-\mathrm{m}$ depth interval. The oversampled, maximal depth interval (i.e., depth of the lower undisturbed reflector) is consistent with the thickness of the perturbed zones observed on the AMS and penetrometry profiles [Labeyrie et al., 2003]. In core MD99-2246, for instance, we found a thickness of $9.4 \mathrm{~m}$ for the former, while AMS and penetrometry profiles indicate a thickness of $9 \mathrm{~m}$ for the perturbed interval (Figures 1 and 3). We observe an excess material thickness of about $5.4 \mathrm{~m}$ in the first $18.3 \mathrm{~m}$ of core MD992227 (open square), $3.5 \mathrm{~m}$ in the first $9.4 \mathrm{~m}$ of core MD99- 


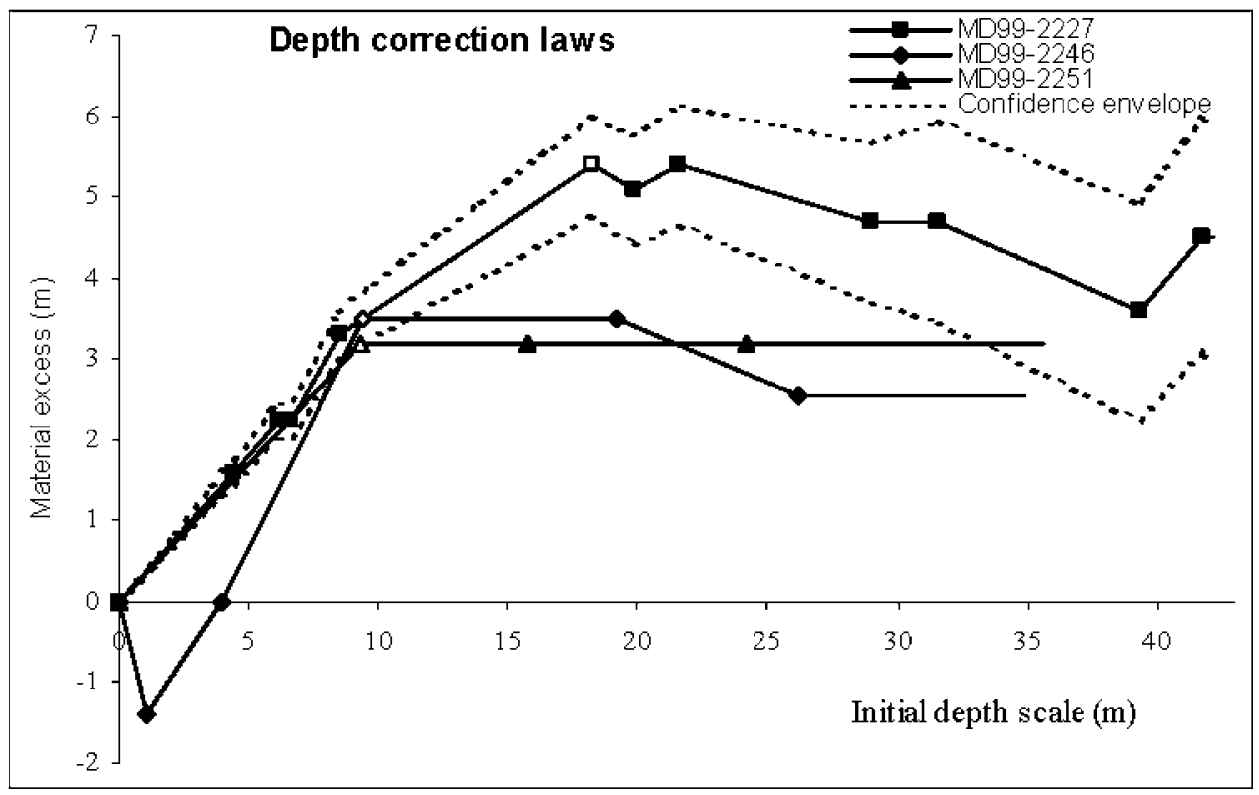

Figure 4. Depth correction curves. For the three cores, we present, as a function of initial (uncorrected) depth scale, the cumulative excess of material (in meters) that has to be corrected to retrieve the true, in situ depth scale (solid squares for core MD99-2227, solid diamonds for core MD99-2246, and solid triangles for core MD99-2251). Symbols indicate the positions of the reflectors used for resynchronization. Open symbols indicate the values used to estimate the average oversampling rate in the upper part of each core. Dashed lines present the confidence envelope obtained considering a maximum error of $\pm 50 \mathrm{~m} \mathrm{~s}^{-1}$ on velocity $\log$ from core MD99-2227.

2246 (open diamond), and $3.2 \mathrm{~m}$ in the first $9.3 \mathrm{~m}$ of core MD99-2251 (open triangle). The corresponding oversampling rates range between 30\% (core MD99-2227) and 37\% (core MD99-2246) (34\% for core MD99-2251).

[19] Oversampling in the upper part of giant piston cores may result from a "syringe effect." This scenario rests upon the idea that after the release of a heavy corer the elastic rebound of the corer cable may result in the upward movement of the piston, which would drain excess side sedimentary material into the liner while the corer enters the upper part of the sediment series. To test this hypothesis, a simple numerical model was developed to look at the relative motion of the corer and the piston during the beginning of a coring procedure (P. Gautron and D. Gourdon, personal communication, 2001). This model solves kinetic equations that take into account the elastic modulus of the Calypso corer cable, the settings of the computed corer being identical to those at our IMAGES sites (i.e., free fall of $1.5 \mathrm{~m}$, corer overall weight of $8500 \mathrm{~kg}$ ). Calculations show that shortly after the corer is released $(t<0.1 \mathrm{~s})$, the elastic rebound of the corer cable forces the piston to go up at high speed $(\sim 5 \mathrm{~m} / \mathrm{s})$. Thus a few meters of the liner can be filled with water before the corer starts entering the sediments (i.e., $\sim 4 \mathrm{~m}$ at 4000 - $\mathrm{m}$ water depth). In the model, the piston's upward displacement stops as soon as the elastic rebound wave front reaches the sea surface. At the water depth of our sites, the elastic rebound has not cancelled out when the corer penetrates the sediments. The piston may still travel upward for $\sim 2 \mathrm{~m}$ as the corer enters the upper part of the sedimentary series, thus acting to force excess material to be drained in the core liner ("syringe effect").
This vertical motion of the piston during corer penetration is smaller than the excess material thickness that we estimated for cores MD99-2227, MD99-2246, and MD992251. It should be noted, however, that the model does not take into account slowing down of the elastic rebound wave due to friction within the water column. If such an effect were included in the model, this would increase the time during which the piston moves upward, allowing therefore more of this upward displacement to take place while the corer penetrates the sediments.

[20] A closer examination of the upper part of the depth correction curves proposed in Figure 3 also indicates the occurrence of a few "compressed" events (negative slopes: for example, the very top of core MD99-2246). Although these tendencies are still poorly constrained (only a few tie points) and need further investigation, they are not intuitively surprising considering the complex physics of a coring operation during which sediment layers with different physical behaviors are successively sampled along the corer pathway. Moreover, the corer may start to penetrate the sedimentary series while the piston is still blocked at the corer end. As a consequence, the very upper part of the series would be incompletely sampled, a feature that has been observed in several sedimentary records obtained through piston coring. Such a scenario, in which the piston has not been released yet while the corer enters the sediments, may appear to conflict with the results of the elastic rebound model discussed above. However, different factors could be invoked to reconcile them, such as, for instance, the slowing down of the elastic rebound wave in the water 
(not taken into account in the model), extra length given to the piston cable loop, which is set up to account for the corer free fall, or an abnormal resistance of the pins that secure the piston at the base of the liner.

[21] In the deepest part of the series, Figure 3 also shows a slight negative slope in the depth correction curves of two of the three cores (especially for core MD99-2227). This slight negative slope is not as pronounced as the upper core oversampling rate, but it is significant according to a Student test. This tendency may indicate that the lower part of some series may be slightly shortened. One possible explanation could be that when the giant piston corer is already largely filled with sediments, it cannot easily sample additional material because of friction effects on the liner. Consequently, deep sediment layers would be only partially retrieved by giant piston coring, which may result in the loss of specific stratigraphic intervals. However, one should remain cautious about that undersampling scenario. For core MD99-2227 we plotted in Figure 4 an estimation of a confidence envelope (dashed lines) for the depth correction curve. This confidence envelope was obtained by assuming a maximum error of $\pm 50 \mathrm{~m} \mathrm{~s}^{-1}$ on the velocity profile. While conclusions remain unchanged concerning the upper core oversampling tendency (positive slope), the cumulative delay resulting from a global underestimation of $P$ wave velocities can clearly flatten the slight negative tendency observed in the lower part of the series, which then does not appear to be significantly disturbed. Thus additional pieces of evidence are needed to confirm the undersampling scenario at the base of long piston cores.

\section{Conclusions}

[22] In this study, we propose a new approach to display, estimate, and correct the depth-scale discrepancies due to oversampling affecting the upper part of sedimentary series during giant piston coring. The method is based on the resynchronization of synthetic seismograms computed from high-quality physical property logs to the corresponding $3.5-\mathrm{kHz}$ chirp profiles. We studied three cores retrieved during the IMAGES V cruise of the R/V Marion Dufresne in the North Atlantic (cores MD99-2227, MD99-2246, and MD99-2251). In the three cases, an oversampling effect is observed in the first $10-18 \mathrm{~m}$ of the series. These intervals correspond to the perturbed zones showing anomalous penetrometry and/or AMS values [Labeyrie et al., 2003].
First estimates for oversampling rates range between $30 \%$ and $37 \%$.

[23] The resynchronization method is limited to sedimentary environments in which strong and well-defined acoustic reflectors are seen in $3.5-\mathrm{kHz}$ profiles and depends also on our ability to confidently identify and match those reflectors to their counterparts in the corresponding synthetic seismograms.

[24] Repeating this approach for different sedimentary environments, with different corer settings, should provide major clues for understanding what is happening during giant piston coring and what the implications are for the recovery of sedimentary series. On the basis of modeling results (P. Gautron and D. Gourdon, personal communication, 2001) it appears that the corer could act as a syringe and may pump an excess of sediment during the elastic rebound of the cable. Several studies could be performed to test this hypothesis. The possibility of equipping the Calypso corer of the R/V Marion Dufresne with accelerometers to get in-time and in situ pieces of information about coring mechanisms would be among the most valuable approaches.

[25] Improper recovery of sedimentary series may also occur with other coring and drilling devices (i.e., compression with gravity cores, incorrect splicing of ODP cores). Additionally, for long sedimentary sections retrieved during ODP drillings, the removal of overburden pressure may also result in the expansion of sediments (i.e., elastic rebound, gas expansion). For calculation of sedimentary rates and fluxes, it is essential to correct for those possible depth-scale drawbacks. The resynchronization approach may provide an independent control on the in situ thickness of sedimentary series.

[26] Acknowledgments. We thank K. Guibert and L. Mayer for their key contribution in the development of the synthetic seismogram modeling routine. K. Kissel, V. Scao, F. Dubois, and all the cruise staff of Leg 2 are thanked for AMS, penetrometry, and MST measurements; the team from the Institut Polaire Français-Paul Emile Victor (IPEV) is thanked for the $3.5-\mathrm{kHz}$ acquisition; and the crew of the R/V Marion Dufresne is thanked for coring operations. We are grateful to $\mathrm{H}$. Thomas and C. Gervaise for their invaluable help in the processing of the $3.5-\mathrm{kHz}$ files. Finally, we thank E. Cortijo for her help in the lithological description of core MD992251, which was not described on board during the InterPole MD99-114/ IMAGES V cruise. Financial support was given by the CNRS/CEA and the French Ministry of Industry through the SIMBA project (European Eureka program). This is LSCE contribution 1021.

\section{References}

Bassinot, F. C., L. D. Labeyrie, E. Vincent, X. Quidelleur, N. J. Shackleton, and Y. Lancelot (1994), The astronomical theory of climate and the age of the BrunhesMatuyama magnetic reversal, Earth Planet. Sci. Lett., 126, 91-108.

Bassinot, F., N. Széréméta, C. Kissel, Y. Balut, K. Guibert, F. Dubois, L. Labeyrie, C. Laj, and M. Pagel (2001), New insights into the oversampling of sedimentary series collected through piston coring, paper presented at EUG XI Meeting, Eur. Union of Geosci., Strasbourg, France.

Breitzke, M. (2000), Physical properties of marine sediments, in Marine Geochemistry, edited by $\mathrm{H}$. O. Schulz and M. Zabel, pp. 29-72, Springer-Verlag, New York.

Buvkley, D. E., W. G. McKinnon, R. E Cranston, and H. A. Christian (1994), Problems with piston core sampling mechanical and geochemical diagnosis, Mar. Geol., 117, 95-106.

Hamilton, E. L. (1971), Prediction of in-situ acoustic and elastic properties of marine sediments, Geophysics, 36, 266-284.

Labeyrie, L., E. Jansen, and E. Cortijo (2003), MD114/IMAGES-V cruise report, Rapp. Camp. Mer OCE/2003/02, 850 pp., Inst. Polaire Fr. Paul Emile Victor, Plouzané, France.
Mayer, L. A. (1980), Deep-sea carbonates: Physical property relationships and the origin of high-frequency acoustic reflectors, Mar. Geol., $38,165-183$.

Mayer, L. A., T. H. Shipley, R. H. Wilkens, and E. L. Winterer (1985), Seismic modeling and paleoceanography at Deep Sea Drilling Project Site 574, Init. Rept. Deep Sea Drill. Proj., 85, 947-970.

Parker, W. R., and G. C. Sills (1990), Observation of corer penetration and sample entry during gravity coring, Mar. Geophys. Res., 12, $101-107$.

Shackleton, N. J., M. A. Hall, and E. Vincent (2000), Phase relationships between millen- 
nial-scale events $64,000-24,000$ years ago, Paleoceanography, 15, 565-569.

Siedler, G., and H. Peters (1986), Physical properties of sea water, in Oceanography, LandoltBörnstein New Ser, group V, vol. 3a, edited by J. Sündermann, pp. 233-264, Springer-Verlag, New York.

Skinner, L., and I. N. McCave (2001), Extensional distortion in a Calypso piston core from the Iberian Margin, paper presented at EUG XI Meeting, Eur. Union of Geosci., Strasbourg, France.

Széréméta, N., F. Bassinot, C. Kissel, Y. Balut, K. Guibert, F. Dubois, C. Laj, and M. Pagel (2000), Stretching of sedimentary series collected through piston coring: Evidence, implications and corrections (abstract), Eos Trans. $A G U, 81(48)$, Fall Meet. Suppl., F708.
Visser, K., R. Thunell, and L. Stott (2003), Magnitude and timing of temperature change in the Indo-Pacific warm pool during deglaciation, Nature, 421, 152-155.

Weber, M. E. (1998), Estimation of biogenic carbonate and opal by continuous non-destructive measurements in deep-sea sediments: Application to the eastern equatorial Pacific, Deep Sea Res., Part I, 45, 1955-1975.

Weber, M. E., F. Nissen, G. Kuhn, and M. Wiedicke (1997), Calibration and application of marine sedimentary physical properties using a multi-sensor core logger, Mar. Geol., 136, 151-172.

Y. Balut, Institut Polaire Français Paul Emile Victor, Technopôle Brest-Iroise, BP 75, F-29280
Plouzané Cedex, France. (yvon.balut@ifrtp. ifremer.fr)

F. Bassinot, Department of Earth Sciences, University of Cambridge, Downing Street, Cambridge CB2 3EQ, UK. (fbas02@esc. cam.ac.uk)

L. Labeyrie, LSCE-Valleé, laboratoire mixte CEA-CNRS, Bâtiment 12, Avenue de la Terrasse, F-91198 Gif-sur-Yvette Cedex, France. (laurent.labeyrie@1sce.cnrs-gif.fr)

M. Pagel, UMR CNRS-UPS 8616 OrsayTerre, Département des Sciences de la Terre, Université Paris-Sud, Bâtiment 504, F-91405 Orsay Cedex, France. (pagel@geol.u-psud.fr)

N. Széréméta, LSCE-Orme, laboratoire mixte CEA-CNRS, Bâtiment 709, Orme des Merisiers, F-91191 Gif-sur-Yvette Cedex, France. (emprin@1sce.saclay.cea.fr) 